ISSN: 2146-3042

DOI: $10.25095 /$ mufad.465937

\title{
Cari Açık Değerleri CDS Puanları Üzerinde Etkili midir? Türkiye İçin Bir Perspektif
}

Cumhur ŞAHIN*

\section{ÖZET}

Bu çalışmada, Türkiye'nin kredi temerrüt takası puanlarıyla cari açık rakamları arasındaki ilişsi incelenmiştir. Bu inceleme kapsamında çalışmanın amacı Türkiye'nin cari işlem açık rakamlarının, kredi temerrüt takası puanlarındaki değişimleri açıklayan öncü bir gösterge olup olmadı̆̆ını ortaya koyabilmektir. 2005M01 - 2017M11 döneminin ele alındı̆̆ çalışmanın ilk aşamasında serilerin durağanlıkları Carrion-i-Silvestre (2009) çoklu yapisal kırlmalı birim kök yöntemiyle test edilmiştir. Daha sonra değişkenlerin birbirleriyle olan uzun dönem ilişkilerinin analiz edilmesinde eşbütünleşme testleri kullanılmıştır. Uzun dönemli ilişkiye ait katsayılar belirlendikten sonra modelin diagnostik testlerine bakılarak modelin uygunluğuna karar verilmiştir. Değişkenler arasında kısa dönemli ilişkilerin belirlenmesinde ARDL'ye dayanan bir hata düzeltme modeli kullanılmıştır. Son aşamada ise TodaYamamoto yöntemi yardımıyla değişkenler arasındaki nedensellik ilişkisi ortaya konmuştur. Elde edilen bulgulara göre de Türkiye’nin cari açık rakamlarının Türkiye kredi temerrüt takası puanlarındaki değişimleri açıklayan bir öncü gösterge olarak ele alınabileceği sonucuna ulaşılmıştır.

Anahtar Kelimeler: Cari Açık, Kredi Temerrüt Takası, Çoklu Yapısal Kırılmalı Eşbütünleşme

JEL Sınıflandırması: F30, E24, G15

\section{Does Current Account Deficit Influence CDS Points? A Perspective For Turkey? \\ ABSTRACT}

In this study, the relationship between Turkey's credit default swap points and the current account deficit figures were examined. Within the scope of this investigation, the aim of the study is to reveal whether Turkey's current account deficit figures is a leading indicator describing the changes in the Turkey's CDS points. The study discussing 2005M01 - 2017 M 11 periods was conducted. In the first stage, the stability of the series was tested by Carrion- i-Silvestre (2009) multiple structural break unit root method. Afterwards, cointegration tests were used in analyzing the long term relationships of the variables with each other. After determining the coefficients of the long-term relationship, the suitability of the model was determined by checking on the model's diagnostic tests. An error correction model based on ARDL was used in identifying the short-term relationships between variables.

In the final stage, the causality relationship between the variables was revealed through the instrument of Toda-Yamamoto method. According to the findings, it was concluded that Turkey's current account deficit figures could be taken as a leading indicator describing the changes in Turkey's CDS points.

Keywords: Current Account Deficit, Credit Default Swap, Multiple Structural Breaks Cointegration.

Jel Classification: F30, E24, G15

\footnotetext{
${ }^{*}$ Dr. Öğr. Üyesi Cumhur Şahin, Bilecik Şeyh Edebali Üniversitesi Bozüyük Meslek Yüksekokulu
} 


\section{GİRIŞ}

Kredi riski, borçlunun finansal işlem dolayısıyla yükümlü olduğu ödemeleri gerçekleştirememesi riskidir. Kredi riskini azaltmaya yönelik uygulamaların en yaygın olanı ise özellikle 1990'lı yıllardan itibaren hızlı bir gelişim gösteren ve kredi türevi olarak adlandırılan işlemlerdir. Kredi türevleri, krediden kaynaklanan kayıplara güvence veren finansal sözleşmelerdir. Bu sözleşmeler, bankalara borç verenlere ve yatırımcılara kredi riski yönetiminde yeni faydalar sunmaktadır.

Kredi türevleri; kredi temerrüt swapları, krediye dayalı tahviller, kredi spread opsiyonları ve toplam getiri swapları olmak üzere dört ana grupta toplanmaktadır (Dufey Rehm, 2000: 3). Kredi temerrüt swapı, bir tarafın, belirli bir referans kurumun ihraç ettiği tanımlanmış referans varlıkların temerrüde düşme riskini, periyodik prim ödemeleri karşılığında, diğer bir tarafa transfer ettiği bir sözleşmedir (Brandon ve Fernandez, 2004: 7).

Kredi temerrüt takası (Credit Default Swap - CDS) en dar tanımıyla kredi riskini etkin bir biçimde yönetme amacı taşıyan bir çeşit finansal sigorta sözleşmesi, en geniş tanımıyla ise herhangi bir finansal kredinin geri ödenmeme riskine karşı alacaklı tarafin parasını koruma altına alan, bunu da belli bir bedel (sigorta primi) karşılığında yapan kredi türev enstrümanına verilen isimdir. Kredi riski taşıyan bir finansal varlığın potansiyel getirisinin, üzerinde önceden anlaşılan belli bir seviyenin altına düşme riskine karşı, o varlığın kendisine dokunmaksızın, söz konusu riski başka bir kişiye/gruba transfer etmeye yarayan ve başka bir finansal üründen hareketle türetilen finansal sözleşme tipine kredi türevi adı verilir (Kunt ve Taş, 2008: 78-89).

Devlet kredi temerrüt takasları ise, devlet tüzel kişiliğinin borçlarını ödememesi durumunda gerçekleşebilecek kredi olaylarındaki kayıplara karşı sigorta görevi gören finansal sözleşmelerdir. Koruma satın alan taraf, olası kredi olayı için sözleşmede belirtilmiş olan tutar başına bir baz puan üzerinden bir prim öder. Koruma satan taraf ise olası kredi olay1 gerçekleştiğinde karşı tarafa sözleşmede belirtilen tutarı öder. Devlet ve şirket kredi temerrüt takaslarının her ikisinde de 5 belirgin özellik sözkonusudur. Bunlar; 1) Borçlanan taraf 2) Bir dizi yükümlülükler 3) Sözleşme vadesi (örneğin 5 yll gibi) 4) Esas tutar ve 5) Koruma ödemesini tetikleyen olaylar listesidir (Markit, 2008). 2013 y1lı sonu itibariyle dünya CDS hacmi yaklaşık 12.7 Trilyon \$ değerine ulaşmıştır (https://www.bis.org/publ/otc_hy1711.pdf).

Görüldüğü gibi finansal alanda risk kavramı son derece önemli bir yer tutmaktadır. Ülkelerin finansal risk düzeyinin göstergesi olarak kredi notlarının belirlenmesinde uzun yıllar boyunca çeşitli kredi değerleme kuruluşlarının notları belirleyici olmuştur. Ancak, özellikle 2008 yılındaki mortgage kökenli küresel krizle birlikte kredi değerleme kuruluşları itibar kaybına uğramışlardır. Çünkü derecelendirme kuruluşları tarafından açıklanan kredi riskini yansıtmada kullanılan kredi notlarının yetersiz olduğu düşüncesi yaygınlaşmıştır. Bundan dolayı kredi riski göstergesi olarak kredi notlarının yerine kullanılabilecek bir başka enstrümana gerek duyulmuştur. Bu aşamada sözkonusu boşluğu doldurmada Kredi Temerrüt Takası (CDS) önem kazanmaya ve ön plana çıkmaya başlamıştır. $\mathrm{Bu}$ önemi ortaya koyabilmek amacıyla çalışmanın takip eden aşamasında kredi temerrüt takası (CDS)'nı konu edinen çalışmalar incelenmiştir. 


\section{LITERATÜR TARAMASI}

Makroekonomik değişkenlerle, varlıkların temerrüde düşme riski arasındaki ilişkiler öteden beri birçok araştırmacının ilgisini çekmiştir. Bu bağlamda başta Black ve Scholes (1973), Merton (1974), Black ve Cox (1976), Brennan ve Schwartz (1980), Chen ve diğerleri (1986), Officer (1973), Schwert (1989), Longstaff ve Schwartz (1995), Hamilton ve Lin (1996), Lando (1998), Duffie ve Singleton (1999), Duffie ve diğerleri (2003), Giesecke ve Weber (2004), Pan ve Singleton (2008), Diebold ve Y1lmaz (2008), Genberg ve Sulstarova (2008), Beber ve Brandt (2009) ile Azad ve diğerleri (2011)'nin yapmış oldukları çalışmalar başta olmak üzere birçok araştırma sözkonusudur. Son zamanlarda makroekonomik değişkenlerle CDS puanları arasındaki ilişkileri ele alan çalışmaların artmaya başlaması da dikkat çekmektedir.

Tang ve Yan (2010)'ın çalışmalarında, CDS puanı ile GSMH, sanayi üretimi ve GSMH büyüme oranı arasındaki ilişkiler incelenmiştir. Verilere ait inceleme dönemi Haziran 1997 ile Kasım 2006 dönemidir. Veriler analiz edildiğinde CDS puanı ile GSMH büyüme oranı ve sanayi üretimi arasında anlamlı ve negatif yönlü bir ilişki, CDS puanı ile GSMH büyüme volatilitesi arasında ise anlamlı ve pozitif yönde bir ilişki olduğu sonucuna varılmıştır.

Eyssell ve diğg. (2013) Çin Devlet CDS 'lerinin belirleyicileri ve fiyat keşfi ile ilgili çalışmalarında Ocak 2001 ile Aralık 2010 döneminde CDS puanları ile makroekonomik ve küresel değişkenler arasındaki ilişkiler incelenmiştir. Makroekonomik değişkenlerden hisse senedi endeksi ile CDS puanı arasında anlamlı ve negatif yönlü bir ilişki, reel faiz oranı ile CDS puanı arasında anlamlı ve pozitif yönlü bir ilişki, borsa volatilitesi ile CDS puanı arasında anlamlı ve pozitif yönlü bir ilişki, borçların milli gelire oranı ile CDS puanı arasında da yine anlamlı ve pozitif yönde bir ilişki olduğu belirlenmiştir.

Naifar ve Abid (2006)'in CDS oranlarının belirleyicileri ile ilgili çalışmalarında, Belçika, Almanya, İtalya, Fransa, Hollanda, Polonya, Portekiz, İspanya, İsveç, İsviçre ve Birleşik Krallık’taki 73 sözleşme incelenmiştir. İnceleme dönemi 15 Mayıs 2000 ile 15 Mart 2001 arasıdır. Analizler neticesinde CDS puanı ile gösterge faiz oranı arasında anlamlı ve negatif yönlü, CDS puanı ile borsa volatilitesi arasında ise anlamlı ve pozitif yönlü bir ilişki olduğu görülmüştür.

Aizenman ve diğ. (2013)'nin CDS puanları, mali olanaklar ve piyasa risk fiyatlaması ile ilgili çalışmalarında İspanya, İtalya, Yunanistan, Portekiz ve İrlanda'da 2008 küresel krizi öncesi ve sonrasındaki dönem için CDS puanları ile bazı makro ekonomik değişkenler arasındaki ilişkileri incelemişlerdir. Bağımlı değişken 5 yıl vadeli CDS puanı, bağımsız değişkenler ise dış borçların vergi gelirlerine oranı, bütçe açığının vergi gelirlerine oranı, diş borçların GSMH'ye oranı, ticari açıklık (ihracat ve ithalat toplamının GSMH'ye oranı) ve enflasyon oranıdır. İnceleme dönemi 2005 ile 2011 arasıdır. Veriler analiz edildiğinde tüm makroekonomik değişkenler ile CDS puanı arasında anlamlı ve pozitif yönlü bir ilişki olduğu, kriz döneminde bu korelasyonun kriz sonrası döneme göre daha da yüksek olduğu görülmüştür.

Norden ve Webber (2009)'in, CDS primleri ile tahvil ve hisse senedi piyasaları arasındaki ilişkiyi inceledikleri çalışmada VAR yönteminden yararlanmışlardır. İnceleme 
dönemi 2000-2002 arasıdır. Bu araştırmacılar, CDS primlerinin tahvil piyasalarına kıyasla hisse senedi piyasalarına daha duyarlı olduğunu ayrıca bu duyarlılığın düşük kredi derecesi için yükseldiğini bulmuşlardır. Bunun yanı sıra bu duyarlılık ABD firmalarında Avrupa firmalarına göre daha yüksektir.

Arouri ve diğ. (2014) bankacılık, finansal hizmetler ve sigorta sektörünü kapsayan ABD 5 yıllık finansal CDS puanlarının dinamik ilişkilerini inceleyen bir çalışma yapmışlardır. İnceleme dönemi 1 Ocak 2004 ile 13 Temmuz 2011'dir. Çalışmalarında kontrol değişkeni olarak ele alınan federal fon faiz oranı, ham petrol fiyatı, hazine bonosu faiz oranı ile CDS puanları arasında anlamlı bir ilişki olmadığı, buna karşın VIX endeks değeri ile CDS puanları arasında anlamlı ve pozitif yönlü bir ilişki belirlenmiştir.

Ericsson ve diğ. (2009)'nin CDS puanının belirleyicileri ile ilgili çalışmalarında firmaların CDS puanları ile kaldıraç, tahvil faizi ve borsa volatilitesi arasındaki ilişkiler ele alınmıştır. Verilere ait inceleme dönemi 1999-2002 arası döneme ilişkin haftalık değerlerdir. Verilerin analizinde doğrusal regresyon yöntemi kullanılmıştır. Veriler analiz edildiğinde CDS puanı ile kaldıraç derecesi ve borsa volatilitesi arasında anlamlı ve pozitif yönlü, CDS puanı ile tahvil faizi arasında ise anlamlı ve negatif yönlü bir ilişki gözlenmiştir. Kredi değerliliği düşük olan firmaların CDS puanlarının faiz oranlarına olan duyarlılığının kredi değeri yüksek firmalara oranla çok daha yüksek olduğu görülmüştür.

Bruneau ve diğg. (2012)'nin İspanya, İtalya, Yunanistan, Portekiz ve İrlanda'daki ekonomik krizi piyasa duyarlılı̆̆ çerçevesinden inceledikleri çalışmalarında, ülke CDS puanlarını bazı makroekonomik değişkenler üzerinden değerlendirmişlerdir. Ele alınan makroekonomik değişkenler, borçların milli gelire oranı, işsizlik düzeyi, birim işgücü maliyeti ve likidite düzeyidir. İnceleme dönemi Ocak 2006 ile Eylül 2011 arasıdır. Veriler analiz edildiğinde borçların milli gelire oranı ile CDS puanı arasında pozitif yönlü, işsizlik düzeyi ile CDS puanı arasında anlamlı ve negatif yönlü, birim işgücü maliyeti ile CDS puanı arasında pozitif yönlü, CDS puanı ile likidite düzeyi arasında ise anlamlı ve negatif yönlü bir ilişki olduğu ortaya konmuştur.

$\mathrm{Pu}$ ve Zhao (2012)'nun kredi risk değişimlerindeki korelasyonla ilgili çalışmalarında bir dizi makro ekonomik değişkenin CDS puanları üzerindeki etkisi araştırılmıştır. Araştırmacıların ele aldığı bağımsız değişkenler, GSMH büyüme oranı, GSMH oynaklı̆̆ı, endüstriyel üretim artışı, endüstriyel üretim oynaklığı, devlet tahvili faiz oranı, VIX endeks değişimi ve enflasyondur. Veriler Ocak 2001 ile Aralık 2006 dönemine ilişkin aylık değerlerdir. 523 firmaya ait CDS değerleri ele alınmıştır. Veriler analiz edildiğinde; GSMH büyüme oranı ile CDS puanı arasında anlamlı ve negatif yönlü, 10 yıllık devlet tahvil getirisi ile CDS puanı arasında anlamlı ve negatif yönlü, GSMH büyüme oranı volatilitesi ile CDS puanı arasında ise anlamlı ve pozitif yönlü bir ilişki olduğu, buna karşın enflasyon oranı ve VIX endeks değişimi ile CDS puanı arasında ise bir ilişki olmadığı sonucuna varılmıştır

Remolona ve diğ. (2008)'nin, yükselen piyasalardaki ülke riskinin dinamik fiyatlamasına ilişkin çalışmalarında Latin Amerika, Merkezi ve Doğu Avrupa, Asya, Ortadoğu ve Afrika'daki 24 ülkenin meydana getirdiği yükselen piyasa ülkelerindeki CDS puanları ile bu puanı etkilediği varsayılan ülkeye özgü risk faktörleri ile küresel risk faktörleri arasındaki ilişkiler incelenmiştir. Bu çalışmadaki veriler Ocak 2002 ile Mayıs 2006 dönemine ilişkindir. Bağımlı değişken olarak Markit veritabanından ulaşılan 5 yıllık CDS 
puanları kullanılmıştır. Ülkeye özgü açıklayıcı değişkenler olarak ise enflasyon, endüstriyel üretim, GSMH büyüme oranı, ihracat artışı ve döviz rezervleri kullanılmıştır. Veriler analiz edildiğinde; enflasyon ile CDS puanı arasında anlamlı ve pozitif yönlü bir ilişki, döviz rezervleri ile CDS puanı arasında ise anlamlı ve negatif yönlü bir ilişki olduğu, buna karşın diğer açıklayıcı değişkenler ile CDS puanı arasında ise bir ilişki olmadığı görülmüştür.

Diaz ve diğ. (2013)'nin şirketlerin CDS piyasasındaki temerrüt risk primlerini etkileyen ekonomik faktörleri araştırdıkları çalışmalarında 2006-2010 dönemi itibariyle 15 Batı Avrupa ülkesinde faaliyet gösteren 85 şirketin CDS değerleri incelenmiştir. Bu çalışmadaki bağımlı değişken 5 yıl vadeli CDS puanları, bağımsız değişkenler olarak ise Avrupa hisse piyasası endeksi, volatilite endeksi, döviz kuru, gecelik faiz oranı ve faiz oranları vade yapısının eğimi kullanılmıştır. Veriler analiz edildiğinde, CDS puanı ile Avrupa hisse piyasası endeksi ve faiz oranları vade yapısı eğimi arasında anlamlı ve negatif yönlü bir ilişki, CDS puanı ile volatilite endeksi, döviz kuru ve gecelik faiz oranı arasında ise anlamlı ve pozitif yönlü bir ilişki olduğu sonucuna ulaşılmıştır.

Fender ve diğ. (2012)'nin bir dizi yükselen piyasa ülkelerinde kredi temerrüt takasının belirleyicilerini inceledikleri çalışmada Doğu Avrupa, Latin Amerika, Güney Afrika ve Asya'daki 12 ülkenin CDS primleri ile bazı makro ekonomik, finansal ve küresel değişkenler arasındaki ilişskiler araştırılmıştır. Bu çalışma iki bölümden oluşur. İlk bölüm küresel kriz öncesi dönem olan Nisan 2002 -Temmuz 2007 ve ikinci bölüm ise küresel kriz sonrası dönem olan Ağustos 2007 ile Aralık 2011 dönemini kapsar. Makro ekonomik değişken olarak ele alınan bütçe açığının milli gelire oranı, dış borçların milli gelire oranı ve gösterge faiz oranıdır. Analizler neticesinde kriz öncesi dönemde makroekonomik değişkenlerle CDS primi arasında anlamlı ve pozitif yönlü bir ilişki olduğu, kriz sonrası dönemde ise CDS primleri ile makroekonomik değişkenler arasında bir ilişki olmadığı, buna karşın küresel değişkenlerin her iki dönemde de CDS primleri üzerinde belirleyici olduğu kanıtlanmıştır.

Longstaff ve diğ. (2011)'nin devlet risk priminin bileşenleri ile ilgili çalışmalarında bir dizi ülkedeki kapsamlı CDS puanları ile bunları etkilediği düşünülen ülkeye özgü ve küresel finansal değişkenler arasındaki ilişki incelenmiştir. Bu çalışmada Ekim 2000 ile Ocak 2010 dönemindeki aylık değişkenlere ilişkin veriler değerlendirilmiştir. Analizler neticesinde yerel hisse senedi piyasa getirisi, döviz kuru ve dış rezervlerin CDS puanı üzerinde etkisi olmasına rağmen, $\mathrm{ABD}$ hisse senedi piyasaları ile $\mathrm{ABD}$ tahvil faiz oranlarının CDS puanı üzerinde çok daha yüksek bir etkisi olduğu gözlenmiştir.

Blau ve Roseman (2014)'ın Birleşik Devletler'in kredi notunun düşürülmesine Avrupa CDS puanlarının reaksiyonunu incelediği çalışmada, 5 Ağustos 2011 tarihinde ABD kredi notunun düşürülmesini izleyen 61 günlük dönemde Avrupa Birliği üyesi olan ve Avrupa Birliği üyesi olmamasına rağmen Avrupa bölgesinde yer alan ülkeler araştırılmıştır. Bağımlı değişken ülke CDS puanları, bağımsız değişkenler ise kişi başına milli gelir, borçların GSMH'ye oranı, ülkelerin nüfusu, döviz kurları ve işsizlik oranlarıdır. Veriler analiz edildiğinde CDS puanı ile kişi başına düşen milli gelir arasında anlamlı ve negatif yönlü, CDS puanı ile borçların GSMH'ye oranı arasında anlamlı ve pozitif yönlü, CDS puanı ile döviz kurları arasında anlamlı ve pozitif yönlü, yine CDS puanı ile işsizlik oranı arasında anlamlı ve pozitif yönlü bir ilişki olduğu, buna karşın CDS puanı ile ülke nüfusu arasında ise anlamlı bir ilişki olmadığı sonucuna ulaşılmıştır. 
Zhang ve dĭg. (2009)'nin hisse senedi volatilitesi ve bireysel firmaların sıçrama riskleriyle CDS puanlarını inceledikleri çalışmalarında, ABD'deki 307 firmanın Ocak 2001 ile Aralık 2003 dönemindeki 5 yıl vadeli CDS puanlarını etkilediği düşünülen firmaya özgü ve makro finansal değişkenler arasındaki ilişkiler incelenmiştir. $\mathrm{Bu}$ bağlamda ele alınan değişkenler hisse senedi piyasa getirisi, piyasa getirisinin volatilitesi, 3 aylık hazine bonosu faiz oranı ve getiri eğrisinin eğimidir. Veriler analiz edildiğinde, CDS puanları ile piyasa getirisi arasında anlamlı ve negatif yönlü, CDS puanı ile piyasa getirisinin volatilitesi arasında ise anlamlı pozitif yönlü bir ilişki olduğu, buna karşın CDS puanları ile hazine bonosu faiz oranı ve getiri eğrisi eğimi arasında ise anlamlı bir ilişkiye rastlanmadığı görülmüştür

Chan ve Marsden (2014)'in CDS indislerinin makro risk faktörleriyle ilgili çalışmalarında, Kuzey Amerika' daki 125 şirketin CDS değerleriyle bazı makro ekonomik risk faktörleri arasındaki ilişsiler araştırılmıştır. Bu çalışma 3 Kasım 2003 ile 8 Temmuz 2011 arasındaki dönemi kapsamaktadır. Veriler analiz edildiğinde, CDS puanı ile ABD ulusal borcun özkaynaklara oranı arasında anlamlı ve pozitif yönlü, CDS puanı ile VIX endeksi arasında anlamlı ve pozitif yönlü, CDS puanı ile getiri eğrisinin eğimi arasında anlamlı ve pozitif yönlü ve CDS puanı ile uzun vadeli tahvil faiz oranı arasında ise anlamlı ve negatif yönlü bir ilişki olduğu belirlenmiştir.

Literatür incelemesi genel olarak değerlendirildiğinde, çalışmaların genel olarak CDS puanlarındaki değişimleri açıklayan makro ekonomik faktörlerin neler olabileceğine yoğunlaşan çalışmalar olduğu görülmektedir. Enflasyon, reel faiz oranları, döviz rezervleri, döviz kurları, dış borçlar, bütçe açıkları, sanayi üretimi, ihracat ve en önemlisi ülkelerin GSMH artış hızlarındaki olumsuzluklar ülke CDS puanının artmasına neden olmaktadır. Diğer ifadesiyle CDS puanları ülkenin temel makro ekonomik değişkenlerindeki gidişatı yansıtan toplulaştırılmış bir gösterge niteliğindedir.

Mal - hizmet, faktör geliri ve transfer hesabı olmak üzere üç ana kalemden oluşan cari işlemler bilançosunda mal ve hizmet ihracatının ithalatından fazla olması, yatırım gelirindeki artışlar ve elde edilen karşılıksız transferlerin fazlalığı sonucunda meydana gelen artış, cari fazla olarak adlandırılmaktadır. Tersine, cari açık ise, mal ve hizmet ithalatının ihracatından fazla olması, yatırım gelirindeki azalışlar ve diğer ülkelere yapılan karşılıksız transferlerin fazlalığı sonucunda, cari işlemler bilançosunda meydana gelen azalışları temsil etmektedir. (Carbaugh, 2009:348).

Bir ülkenin makroekonomik performansına ilişkin temel göstergelerinden biri olan cari işlemler dengesinde meydana gelen değişmeler, ekonominin gidişatı bakımından sinyal olarak değerlendirilmekte ve dolayısıyla gerek o ülke veya gerekse sözkonusu ülkedeki şirketlerle ilgili olarak muhtemel yatırım kararları ile beklentilerin belirlenmesinde hayati bir rol oynamaktadir.

Bir ülkenin cari işlemler açığının artması, o ülkedeki genel makro ekonomik durumun kötüye gittiğini göstermesi açısından o ülkedeki firmaların dış piyasalardan borçlanma maliyetlerini artırıcı etki yapacaktır. Bu da gerek ülke veya gerek şirket CDS primlerinin yükselmesine yol açabilecektir. Bu gerçeklerden hareketle bu çalışma, Türkiye'nin cari açık rakamları ile ülke CDS puanları arasında bir ilişkinin varlığını, daha geniş açıdan bakılacak 
olursa, Türkiye'nin cari açık değerlerindeki değişimlerin ülke CDS puanlarındaki değişimleri açıklamada bir öncü gösterge olup olmayacağını incelemeye yönelik olarak yapılmıştır.

\section{AMPÍRIK ANALIZ}

\subsection{Veri Seti, Model ve Yöntem}

Bu çalışmada Türkiye'nin cari açık rakamlarının Türkiye CDS puanlarını açıklayıcı özelliği, diğer bir ifadeyle cari açık değerlerinin Türkiye CDS primlerini açıllayan bir öncü gösterge olup olmadığının araştırılması hedeflenmektedir. Bu hedeften hareketle araştırmada Türkiye'nin CDS puanları ve cari açık rakamlarından oluşan iki değişken kullanılmıştır. Araştırma aylık verilerden oluşmakta ve 2005M01 - 2017M11 dönemini kapsamaktadır. CDS verileri Bloomberg veri tabanından, cari açık rakamları ise TCMB web sayfasından temin edilmiştir. Türkiye'nin CDS puanlarındaki değişimlerin işsizlik rakamlarını açıklamada öncü bir gösterge özelliği taşıyıp taşımadığı 1 numaralı eşitliklikte gösterilen model oluşturularak tahminlenmeye çalışılmıştır:

$$
\mathrm{CDS}_{\mathrm{it}}=\mathrm{a}+\mathrm{CA}_{\mathrm{it}}+\varepsilon
$$

CA Türkiye'nin cari açık rakamlarını, CDS ise Türkiye'nin CDS puanlarını göstermektedir.

Çalışmanın ekonometrik analiz bölümü sırasıyla şu aşamalardan oluşmaktadır: Öncelikli olarak CDS rakamları ile cari açık değerleri serisinin durağanlığı Carrion-i-Silvestre vd. (2009) tarafından geliştirilen çoklu yapısal kırılmalı birim kök testiyle araştırılmıştır. Bunun ardından değişkenlerin birbirleriyle olan uzun dönem ilişkilerinin analiz edilmesinde eş bütünleşme testleri kullanılmıştır. Uzun dönemli ilişkiye ait katsayılar belirlendikten sonra modelin diagnostik testlerine bakılarak modelin uygunluğuna karar verilmiştir. Değişkenler arasında kısa dönemli ilişkilerin belirlenmesinde ARDL'ye dayanan bir hata düzeltme modeli kullanılmıştır. Son aşamada ise Toda-Yamamoto yöntemi yardımıyla değişkenler arasındaki nedensellik ilişkisi ortaya konmuştur.

\section{2. Çoklu Yapısal Kırılmalar Altında Birim Kök Testi}

Serilere ait birim kökün varlığının araştırıldığı geleneksel ADF, PP ve KPSS gibi birim kök testleri serilerdeki yapısal kırılmaları dikkate almamaktadır. Yapısal kırılma dönemlerini dikkate almayan bu geleneksel yöntemlerde de gerçekte durağan olan seriler için durağan olmadığını gösteren hatalı sonuçlara ulaşılabilmektedir (Perron, 1989). Geleneksel yöntemler serilerin yapısal kırılmaları içermediği varsayımından hareket etmektedir. Ancak gerçek hayatta savaşlar, doğal afetler ve ekonomik krizler gibi değişimler yapısal kırılmalara neden olabilmektedir.

Yapısal kırılmaları da dikkate alan ilk birim kök analizleri Perron (1989) öncülüğünde başlamıştır. Sonrasında Zivot - Andrews (1992), Lumsdaine - Papell (1997), Perron (1997), Bai - Perron (1998), Ng - Perron (2001), Lee - Strazicich (2003 - 2004), Kapetanios (2005) ve Carrion-i-Silvestre vd. (2009) yapısal kırılmaların varlığında birim kök analizi yapabilen alternatif testler geliştirmişlerdir. Bu yeni nesil birim kök testleri olarak adlandırılan bu testler de kendi aralarında iki gruba ayrılmaktadır, Bai - Perron (1998), 
Kapetanios (2005) ve Carrion-i-Silvestre vd. (2009) serilerde çoklu yapısal kırılmalar altında birim kök analizi yapabilirken diğer test yöntemlerinde ise bir ya da en fazla iki yapısal kırılmaya kadar birim kök analizi yapılabilmektedir.

Bu çalışmada Carrion-i-Silvestre vd. (2009) tarafından geliştirilen ve en fazla beş yapısal kırılmanın varlığında birim kök analizi yapabilen test yöntemi kullanılmıştır.

Carrion-i-Silvestre vd. (2009), serilerdeki birim kökün varlığını ifade eden sıfır hipotezini sınamak için 2,3,4,5 ve 6 numaralı eşitliklerde yer alan beş farklı test yöntemi geliştirmişlerdir:

$$
\begin{aligned}
& P_{T}\left(\lambda^{0}\right)=\frac{\left[S\left(\bar{\alpha}, \lambda^{0}\right)-\bar{\alpha} S\left(1, \lambda^{0}\right)\right]}{S^{2}\left(\lambda^{0}\right)} \\
& M_{T}\left(\lambda^{0}\right)=\frac{\left[c^{-2} T^{-2} \sum_{t=1}^{T} \tilde{y}_{t-1}^{2}+(1-\bar{c}) T^{-1} \tilde{y}_{T}^{2}\right]}{S\left(\lambda^{0}\right)^{2}} \\
& M_{\alpha}\left(\lambda^{0}\right)=\left(T^{-1} \tilde{y}_{T}^{2}-S\left(\lambda^{0}\right)^{2}\right)\left(2 T^{-2} \sum_{t=1}^{T} \tilde{y}_{t-1}^{2}\right)^{-1} \\
& M S B\left(\lambda^{0}\right)=\left(S\left(\lambda^{0}\right)^{-2} T^{-2} \sum_{t-1}^{T} \tilde{y}_{t}^{2}\right)^{1 / 2} \\
& M Z_{t}\left(\lambda^{0}\right)=\left(T^{-1} \tilde{y}_{T}^{2}-S\left(\lambda^{0}\right)^{2}\right)\left(4 s\left(\lambda^{0}\right)^{2} T^{-2} \sum_{t-1}^{T} \tilde{y}_{t-1}^{2}\right)^{1 / 2}
\end{aligned}
$$

2,3,4,5 ve 6 numaralı eşitliklerdeki test istatistiklerinde PT; Perron ve Rodriguez (2003) tarafından geliştirilen optimal test istatistiği, MPT ; Ng ve Perron (2001) izlenerek geliştirilen modifiye edilmiş optimal test istatistiği, MZ $\alpha$, MSB ve MZt de Ng ve Perron (2001) ile Perron ve Rodriguez (2003) tarafından geliştirilmiş çoklu yapısal kırılmaya izin veren M-sınıfı (Multiple Structural Breaks: Çoklu Yapısal Kırılmalı) test istatistikleridir.

Eşitliklerdeki, $\lambda^{0}$ kırılmalar vektörünün tahmini ve $S^{2}\left(\lambda^{0}\right), \quad v_{t}$ ile gösterilen hata teriminin izgesel yoğunluğunun sıfır frekansta tahminidir, c, merkezi olmayan parametre iken, $\mathrm{S}\left(\lambda^{0}\right)^{2}$ ise otoregresif tahmin fonksiyonudur.

$\mathrm{Bu}$ testin hipotezleri ise şu şekildedir:

$H_{0}$ : Çoklu yapısal kırılmaların varlığında birim kök vardır.

$H_{1}$ : Çoklu yapısal kırılmaların varlığında birim kök yoktur. 
Değişkenlerin birbirleriyle olan uzun dönem ilişkilerinin analiz edilmesinde eş bütünleşme testleri kullanılmaktadır. Klasik eş bütünleşme testlerinde değişkenlerin aynı dereceden durağan olması gerekmektedir. $\mathrm{Bu}$ durum eş bütünleşme testinin yapılmasında önemli kısıt oluşturmaktadır. $\mathrm{Bu}$ sorun değişkenlerin farklı derecelerden bütünleşik olduklarında da aralarındaki uzun dönemli ilişkinin analiz edilmesine imkân veren ARDL yöntemi ile aşılmaktadır. Peseran vd. (2001)'nin geliştirdiği bu yaklaşım eş bütünleşme testlerinde yaygın olarak kullanılmaktadır (Esen, vd., 2012: 256). 7,8 ve 9 numaralı eşitlikler kullanılarak ARDL modeli ile eş bütünleşme analizi yapılmaktadır.

$$
\Delta C D S_{t}=c_{0}+\sum_{i=1}^{m} c_{1} \Delta C D S_{t-i}+\sum_{i=0}^{n} c_{2 i} \Delta C A_{t-i}+\delta 1 C D S_{t-i}+\delta 2 C A_{t-i}+\varepsilon_{t}
$$

(7) nolu eşitlikte $\Delta$ simgesi fark operatörünü, $c$ simgesi sabit terimi, $\varepsilon$ simgesi ise hata terimini ifade etmektedir. Eş bütünleşme analizinin yapılması için öncelikle (6) no'lu eşitlik tahmin edilmektedir

Uzun dönemli ilişkinin analizi için hesaplanan F istatistik değeri, Pesaran ve Smith'in (2001) çalışmalarında asimptotik olarak türetilen anlamlılık düzeyleri ile karşılaştırılmaktadır. Eğer $\mathrm{F}$ istatistiği kritik değerin üstündeyse $\mathrm{H}_{0}$ reddedilmektedir. Böylece eş bütünleşme ilişkisinin bulunduğu sonucuna ulaşılmaktadır. Modelin eş bütünleşme ilişkisine sahip olduğunun anlaşılmasının ardından uzun dönem katsayıları elde edilmektedir. Uzun dönem katsayılarının tahmininin yapılması için 8 numaralı eşitlikte yer alan ARDL(m, n) modeli oluşturulmaktadır.

$$
C D S_{t}=c_{0}+\sum_{i=1}^{m} c_{1} C D S_{t-i}+\sum_{i=0}^{n} c_{2 i} \Delta C A_{t-i}+\varepsilon
$$

Uzun dönemli ilişkiye ait katsayılar belirlendikten sonra modelin diagnostik testlerine bakılarak modelin uygunluğuna karar verilmektedir. Değişkenler arasında kısa dönemli ilişkilerin belirlenmesinde ARDL'ye dayanan bir hata düzeltme modeli kullanılmaktadır. Bunun için ise (9) no'lu eşitlik tahmin edilmektedir

$$
\Delta C D S_{t}=c_{0}+c_{1} \Delta E C M_{t-1}+\sum_{i=1}^{m} c_{2 i} \Delta C D S_{t-i}+\sum_{\mathrm{i}=0}^{n} c_{3 i} \Delta C A_{t-i}+\varepsilon_{t}
$$

(9) no'lu eşitlikte $E C M_{t-1}$ ile gösterilen değişken hata düzeltme terimidir. Hata düzeltme katsayısı değişkenler arasında uzun dönem ilişkisinin elde edildiği modelin kalıntılarının bir gecikmeli değerini ifade etmektedir. ECMifadesinin katsayısı kısa dönemde meydana gelen bir şokun etkisinin ne kadarının uzun dönemde ortadan kalkacağını göstermektedir (Paseran vd., 2001).

Öte yandan, seriler arasında ilişkilerin, durağanlık ve kointegrasyon önsel bilgisine ihtiyaç duymadan gözlemlenebileceği modeller mevcuttur. Bu modeller arasında TodaYamamoto Yöntemi'nden söz edilebilir. Toda-Yamamoto (1995) Yöntem'inde ilk aşama, VAR modelinde uygun gecikme seviyesinin (p) belirlenmesidir. İkinci aşamada, p gecikmeye, en yüksek integreye sahip değişkenin integre seviyesi (dmax) ilave edilmektedir. Üçüncü aşamada, $p+d m a x$ gecikme için serilerin orjinal değerleri üzerine EKK modeli tahmin edilmektedir. Tahmin edilen eşitlikler tablo 1'de görülmektedir. 
Tablo 1. Carrion-i-Silvestre vd. (2009) Birim Kök Testi Sonuçları

\begin{tabular}{|c|c|c|c|c|c|l|}
\hline \multirow{2}{*}{$C$} & \multicolumn{5}{|c|}{ Düzey Değerleri } & \multirow{2}{*}{ En Fazla 5 Kirılma } \\
\cline { 2 - 6 } & $P_{T}$ & $M P_{T}$ & $M Z_{\alpha}$ & $M S B$ & $M Z_{t}$ & \\
\hline & 17.93 & 15.86 & -27.92 & 0.13 & -3.73 & 2006M04-2007M10 - 2009M02- \\
& {$[9.33]$} & {$[9.33]$} & {$[-46.68]$} & {$[0.10]$} & {$[-4.80]$} & 2013M04- \\
\hline \multirow{2}{*}{$c a$} & $7.98^{*}$ & $6.63 *$ & -59.35 & $0.09 *$ & -5.43 & 2008M06-2011M03-2013M02- \\
& {$[8.55]$} & {$[8.55]$} & {$[-44.98]$} & {$[0.10]$} & {$[-4.73]$} & 2013M11-2015M08-2016M02 \\
\hline
\end{tabular}

\begin{tabular}{|c|c|c|c|c|l|}
\hline \multicolumn{5}{|c|}{ Birinci Farklar } & \\
\hline$\Delta$ CDS & $4.49^{*}$ & $4.30^{*}$ & -21.15 & $0.15^{*}$ & -3.25 \\
& {$[5.54]$} & {$[5.54]$} & {$[-17.32]$} & {$[0.16]$} & {$[-2.89]$} \\
\hline
\end{tabular}

Not: Köşeli parantez içerisindeki değerler 1000 bootstrap döngüsü ile elde edilen kritik değerlerdir. *; \%5 anlamlıllk düzeyinde serinin durağanliğın ifade etmektedir. Test yöntemi olarak sabitte ve trenddeki yapısal kırlmaları gösteren model seçilmiştir. Çalışmada ele alınan veri setinin kısa olmasından dolayı en fazla 3 kirılmaya izin verilmiştir. Ü̧̧ farkl yapısal kurılma tarihi test yöntemi tarafindan içsel olarak belirlenmişstir

Hesaplanan test istatistikleri bootstrapla üretilen kritik değerlerden küçük olduğunda sıfir hipotezinin reddine karar verilir. Sıfır hipotezinin reddedilmesi ilgili serinin yapısal kırılmalar altında birim kök içermediği, diğer bir ifade ile serinin durağan olduğu anlamına gelmektedir. Bu bağlamda CDS serisinin durağanlık seviyesi I(1), cari açığının durağanlık seviyesi I(0) olarak tespit edilmiştir. Bir değişkenin I(1) diğer değişkenin I(0) olması nedeni ile buna uygun bir eş-bütünleşme analizi olan ARDL sınır testi kullanılmıştır.

Tablo 2. Eş- Bütünleşme sonuçları

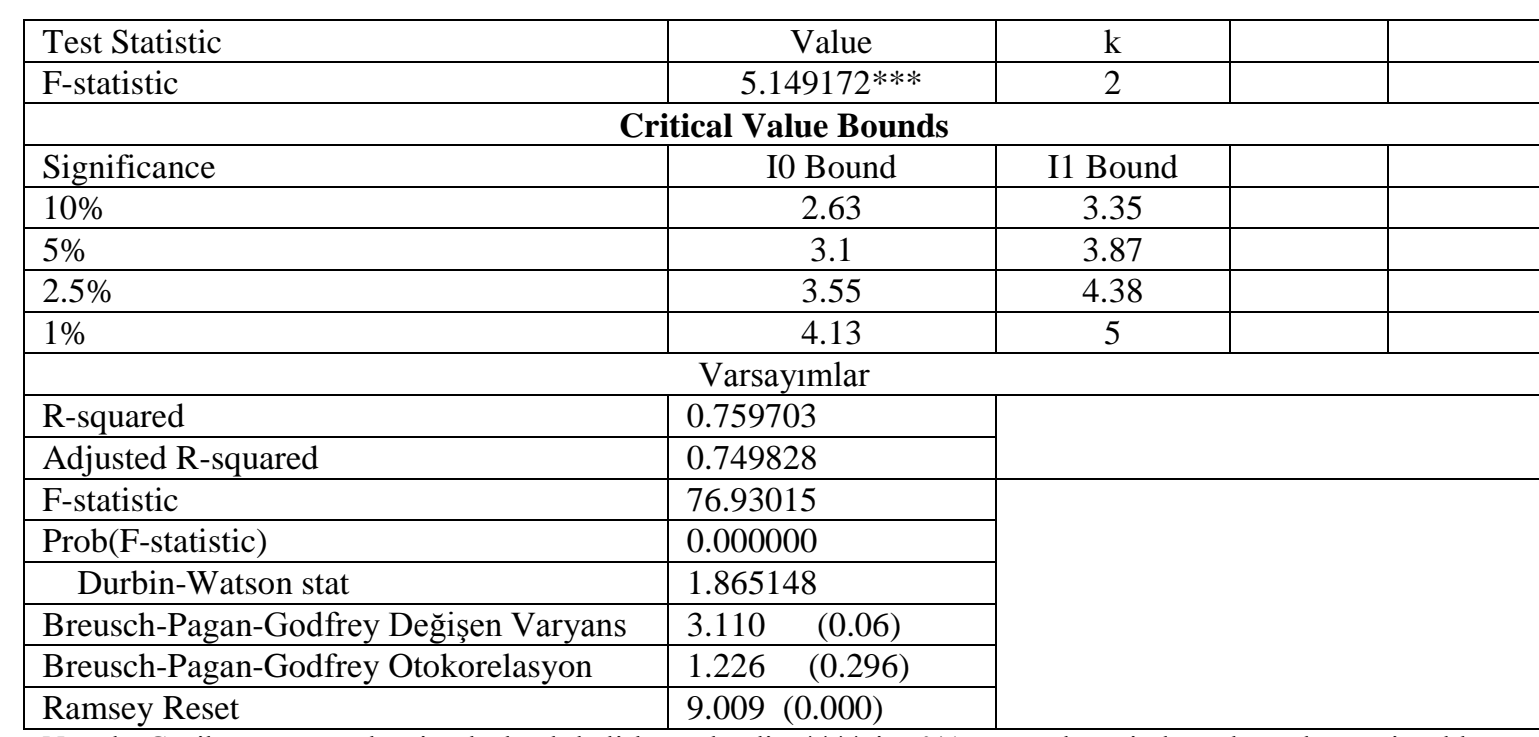

Not: k, Gecikme sayıs1 olup içsel olarak belirlenmektedir, **** ise \%1 önem düzeyinde eş bütünleşmenin olduğunu ifade etmektedir

Tablo 2'ye göre, \%1 anlamlılık seviyesinde hesaplanan F istatistik değeri (5.149172) üst sınır (5.00) değerinden büyük olduğu için $\mathrm{H}_{0}$ hipotezi reddedilmiş, dolayısıyla, değişkenler arasında bir eş-bütünleşme ilişkisinin olduğu tespit edilmiştir. Ayrıca, Tablo 2'de ARDL modelinin tanısal test sonuçları da verilmiştir. Buna göre, modelde herhangi bir otokorelasyon (Breusch-Godfrey LM Testi), değişen varyans (Breusch-Godfrey Testi) sorununun bulunmadığı, ve model kurma hatasının (Ramsey Reset Testi) olmadığ anlaşılmaktadır. 


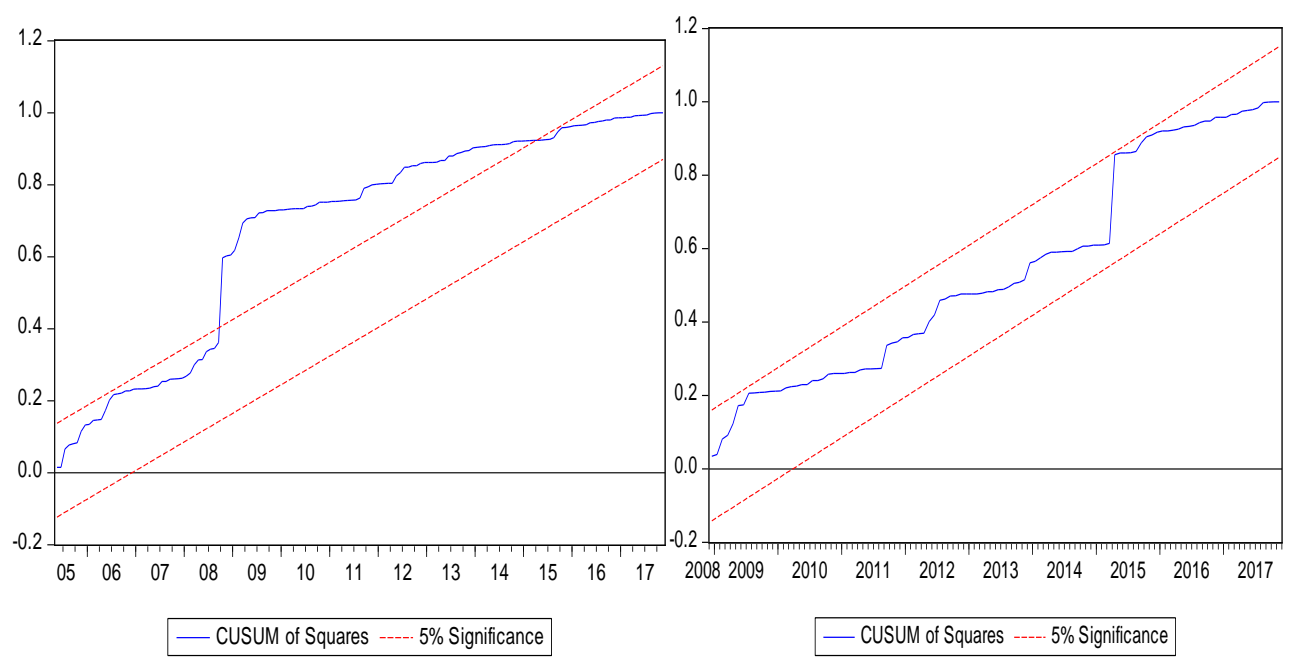

Şekil 1. CUSUMSQ Grafiği

Eğer, CUSUMSQ (Cumulative sum of squares) istatistikleri \%5 anlamlılık düzeyinde kritik sınırlar içerisinde (iki çizgi arasında) kalıyorsa, ARDL modelindeki katsayıların istikrarlı olduğunu ifade eden $\mathrm{H}_{0}$ hipotezi kabul edilecektir (Bahmani-Oskooee, Ng, 2002). Eğer, CUSUMSQ grafikleri sınırların dışında kalırsa, katsayıların durağanlığını savunan $\mathrm{H}_{0}$ hipotezinin reddedilmesi gerekecektir.

Şekil 1'deki CUSUMSQ grafikleri incelendiğinde, analiz kapsamında kullanılan değişkenlere ilişkin bir yapısal kırılma olmadığından, ARDL Sınır Testine göre hesaplanan uzun dönem katsayıların istikrarlı olması için ve kırılmayı ifade etmek üzere d1 değişkeni kullanılarak modelin tahmin edilmesi gerekmektedir. Diğer yandan d 2 değişkeni eklendikten sonra kritik değerlerin çizgi içerisinde dalgalandığı görülmektedir. Bu durum ise katsayıların istikrarlı hale geldiğini göstermektedir.

Tablo 3. Kısa Dönem Eş-Bütünleşme Katsayıları

\begin{tabular}{|c|r|r|r|r|}
\hline Variable & Coefficient & Std. Error & t-Statistic & \multicolumn{1}{c|}{ Prob. } \\
\hline $\mathrm{D}(\mathrm{ca})$ & 0.001717 & 0.001545 & 1.111353 & 0.2682 \\
\hline $\mathrm{D}(\mathrm{ca}(-1))$ & 0.003063 & 0.001572 & 1.947870 & $0.0533^{* *}$ \\
\hline $\mathrm{D}(\mathrm{D} 1)$ & 98.045499 & 23.433284 & 4.184027 & $0.0000^{* * *}$ \\
\hline CointEq(-1) & -0.157206 & 0.034289 & -4.584747 & $0.0000^{* * *}$ \\
\hline \multicolumn{5}{|c|}{ Uzun dönem Katsay1lar1 } \\
\hline Variable & Coefficient & Std. Error & t-Statistic & Prob. \\
\hline ca & 0.014437 & 0.008426 & -1.713407 & 0.0888 \\
\hline $\mathrm{D} 1$ & -54.126972 & 27.606467 & -1.960663 & 0.0518 \\
\hline $\mathrm{C}$ & 197.012676 & 37.905099 & 5.197524 & 0.0000 \\
\hline
\end{tabular}

Not: ***,**,* Sırası ile değişkenler arasındaki $\% 1, \% 5$ ve \%10 önem düzeyinde anlamlı olduklarını ifade etmektedir.

Hata düzeltme katsayısı (ECM-1) beklendiği gibi negatif ve istatistiki olarak anlamlıdır. Bu durum kısa dönemde meydana gelen dengeden sapmaların uzun dönemde dengeye yaklaştı̆ğ anlamına gelmektedir. Uzun dönem katsayıları incelendiğinde ise cari 
açıkta meydana gelen \% 1'lik artışın CDS primlerinde 0.01 baz puanlık artışa neden olduğu tespit edilmiş olup, eklenen kukla değişken negatif ve istatistiki olarak anlamlı bulunmuştur.

Toda ve Yamamoto (1995) nedensellik analizinde değişkenlerin durağanlık düzeyleri olmadığından, çalışmada bu analizin kullanılması daha uygun olarak görülmüştür.

Tablo 4. Toda Yamamoto Nedenselliği

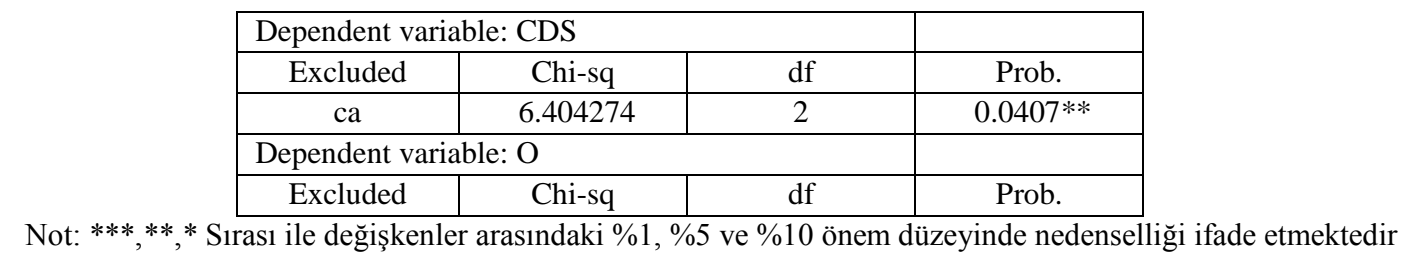

Tablo 4’te görüldüğü üzere, nedensellik analizi sonuçlarına göre cari açık rakamlarından CDS primlerine doğru tek yönlü bir nedensellik tespit edilmiştir.

\section{SONUÇ}

Finansal piyasalardaki aktörler açısından risk son derece önemli bir kavramdır. Genel anlamda risk, objektif olarak belirlenebilen kaybetme olasılığı iken finansal anlamda beklenen getiri ile gerçekleşen getiri arasındaki olumlu veya olumsuz sapmadır. Dolayısıyla özellikle küreselleşme ve sermaye akımlarındaki engellerin kalkmasıyla birlikte 1990'lı yıllardan itibaren uluslararası yatırımcılar riskin saptanmasına çok daha fazla duyarlılık göstermeye başlamışlardır. Bu süreçte telekomünikasyon alanında yaşanan olağanüstü gelişmelerin de etkisiyle finansal araç ve tekniklerin sayısında muazzam artışlar görülmektedir. $\mathrm{Bu}$ finansal risk enstrümanlardan biri de CDS (credit default swap)'lerdir ve temel makro ekonomik değişkenler ile CDS primleri arasındaki ilişkileri inceleyen akademik çalışmalarda son zamanlarda artış gözlenmektedir.

Bu çalışmada ise, Türkiye' nin cari açık rakamlarının ülke CDS puanlarını açıklayıcı özelliği, diğer bir ifadeyle ülke cari açık değerlerinin Türkiye'nin CDS puanlarının öncü göstergesi olup olmadığının araştırılması hedeflenmiştir. Bu hedef doğrultusunda uygulanan ekonometrik analiz şu aşamalardan oluşmuştur: Öncelikli olarak Carrion-i-Silvestre vd. (2009) tarafından geliştirilen çoklu yapısal kırılmalı birim kök testiyle araştırılmıştır. Bunun ardından değiş̧kenlerin birbirleriyle olan uzun dönem ilişkilerinin analiz edilmesinde eş bütünleşme testleri kullanılmıştır. Uzun dönemli ilişkiye ait katsayılar belirlendikten sonra modelin diagnostik testlerine bakılarak modelin uygunluğuna karar verilmiştir. Değişkenler arasında kısa dönemli ilişkilerin belirlenmesinde ARDL'ye dayanan bir hata düzeltme modeli kullanılmıştır. Son aşamada ise Toda-Yamamoto yöntemi yardımıyla değişkenler arasındaki nedensellik ilişkisi ortaya konmuştur. Ulaşılan sonuçlara göre cari açıkta meydana gelen \% 1'lik artışın CDS primlerinde 0.01 baz puanlık artışa neden olduğu tespit edilmiştir. Analizin son aşamasında yer alan hata düzeltme modeline göre de uzun dönem analizleri güvenilir sonuçlar vermektedir.

Elde edilen bulgulara göre; Türkiye'nin cari açık rakamlarındaki değişimler uzun dönemde ülke CDS puanlarındaki değişimleri pozitif yönlü olarak açıklamaktadır. Buna göre 
Türkiye için, cari açık değerlerindeki değişimin ülke CDS puanlarındaki değişimi açıklamada öncü gösterge olarak kabul edilebileceği sonucuna ulaşılmıştır.

\section{KAYNAKLAR}

Abid, Fathi.- Naifar, Nader. (2006), “The Determinants of Credit Default Swap Rates: An Explanatory Study”, International Journal of Theoretical and Applied Finance, Vol 09, pp. 23-42.

Aizenman, J.- Hutchison, M.- Jinjarak, Y. (2013), "What Is The Risk of European Sovereign Debt Defaults? Fiscal Space, CDS Spreads And Market Pricing of Risk”, Journal of International Money and Finance, Journal of International Money and Finance 34, pp.37-59.

Arouri, Mohamed.- Hammoudeh, Shawkat.- Jawadi, Fredj.- Nguyen, Duc Khuong. (2014), "Financial Linkages Between US Sector Credit Default Swaps Markets”, Journal of International Financial Markets, Institutions \& Money, Journal of International Financial Markets, Institutions and Money 33, pp. 223-243.

Azad, A. S. M. S.- Fang, V.- Wickramanayake, J. (2011), "Low-frequency Volatility of Yen Interest Rate Swap Market in Relation to Macroeconomic Risk.” International Review of Finance, 11(3), pp. 353-390.

Bai, J.- Perron, P. (1998), Estimating and Testing Linear Models with Multiple Structural Changes. Econometrica, 66(1), pp. 47-78.

Beber, A.- Brandt, M. W. (2009), "Resolving macroeconomic uncertainty in stock and bond markets.” Review of Finance, 13(1), pp. 1-45.

Black, F.- Scholes, M. (1973), “The Pricing of Options And Corporate Liabilities”. Journal of Political Economy, 81, pp. 637-654.

Black, F.- Cox, J. C. (1976), "Valuing Corporate Securities: Some Effects of Bond İndentures Provisions." Journal of Finance, 31, pp. 351-367.

Blau, Benjamin. M. - Roseman, Brian. S. (2014), “The Reaction of European Credit Default Swap Spreads To The U.S. Credit Rating Downgrade”, International Review of Economics and Finance, 34, pp. 131-141.

Brandon, Kyle. I.- Fernandez, Frank. A. (2004), "Financial Innovation and Risk Management : An Introduction to Credit Derivatives”, SIA Research Reports, Volume: 5, No:13, pp. 52-63.

Brennan, M.- Schwartz, E. (1980), “Analyzing Convertible Bonds”. Journal of Financial and Quantitative Analysis, 15, pp. 907-929.

Bruneau, Catherine.- Delattey, Anne-Laure.- Fouquau, Julien. (2012), "Is the European sovereign crisis self-fulfilling? Empirical evidence about the drivers of market sentiments”, Working Paper. Université Paris X Nanterre. 
Carbaugh, R. J. (2009), International Economics. 12th Edition. USA: Cengage Learning.

Carrion-i-Silvestre, J. L-, Kim, D.- Perron, P. (2009), "GLS-Based Unit Root Tests with Multiple Structural Breaks Under Both the Null and the Alternative Hypotheses”, Econometric Theory, 25, pp. 1754-1792.

Chan, Kam. Fong.- Marsden, Alastair. (2014), "Macro Risk Factors of Credit Default Swap Indices In A Regime-Switching Framework", Journal of International Financial Markets, Institutions \& Money 29 , pp. 285-308.

Chen, N.F.- Roll, R.- Ross, S. A. (1986), Economic forces and the stock market. Journal of Business, 59(3), pp. 383-403.

Díaz, Antonio.- Groba, Jonatan.- Serrano, Pedro. (2013), “ What drives corporate default risk premia? Evidence from the CDS market", Journal of International Money and Finance 37, pp. 529-563.

Diebold, F. X.- Yilmaz, K. (2008), "Macroeconomic volatility and stock market volatility, worldwide.” National Bureau of Economic Research, working paper (pp. 14269).

Dufey, Gunter.- Rehm, Florian. (2000), “An Introduction to Credit Derivatives”, University of Michigan Teaching Note.

Duffie, D.- Singleton, K. (1999), "Modeling Term Structures of Defaultable Bonds.” Review of Financial Studies 12, pp. 687-720.

Duffie, D.- Pedersen, L.- Singleton, K. (2003), "Modeling Sovereign Yield Spreads: A Case Study of Russian Debt.” Journal of Finance 58, pp. 119-159.

Ericsson, J.- Jacobs, K.- Oviedo, R. (2009), “The Determinants of Credit Default Premia”, Journal of Financial and Quantitative Analysis, , 44, pp. 109-132.

Esen, E.- Y1ldırım, Z.- Kostakoğlu, S. F. (2012), "Feldstein-Horioka Hipotezinin Türkiye Ekonomisi İçin Sınanması: ARDL Modeli Uygulaması", Eskişehir Osmangazi Üniversitesi İktisadi ve İdari Bilimler Dergisi, 7(1), ss. 251-267.

Eyssell, Thomas.- Fung, Hung.Gay.- Zhang, Gaiyan. (2013), "Determinants And Price Discovery of China Sovereign Credit Default Swaps”, China Economic Review 24, pp. 1-15.

Fender, Ingo.- Hayo, Bernd.- Neuenkirch, Matthias. (2012), "Daily Pricing of Emerging Market Sovereign CDS Before And During The Global Financial Crisis”, Journal of Banking \& Finance (36), pp. 2786-2794.

Genberg, H.- Sulstarova, A. (2008), "Macroeconomic volatility, debt dynamics, and sovereign interest rate spreads." Journal of International Money and Finance, 27(1), pp. 6-39. 
Giesecke, K.- Weber, S. (2004), “Cyclical Correlations, Credit Contagion and Portfolio Losses”. Journal of Banking and Finance 28, pp. 3009-3036.

Hamilton, J.- Lin, G. (1996), “Stockmarket volatility and the business cycle”. Journal of Applied Econometrics, 5, pp. 573-593.

Kapetanios, G. (2005), “ Unit-Root Testing Against The Alternative Hypothesis of up to m Structural Breaks”, Journal of Time Series Analysis, 26(1), pp. 123-133.

Kunt, Abdullah. Selim.- Taş, Oktay. (2008), “Kredi Temerrüt Swapları ve Türkiye'nin CDS Priminin Tahmin Edilmesine Yönelik Bir Uygulama", İTÜ Sosyal Bilimler Dergisi, Cilt:5, Say1:1, ss. 78-89.

Lando, D. (1998), “On Cox Processes And Credit Risky Bonds”. Review of Derivatives Research 2, pp. 99-120.

Lee, J.- Strazicich, M.C. (2003), "Minimum Lagrange Multiplier Unit Root Test with Two Structural Breaks”, The Review of Economics and Statistics, 85(4), pp. 1082-1089.

Lee, J.- Strazicich, M.C (2004). Minimum Lagrange Multiplier Unit Root Test with One Structural Break. Working Paper, Department of Economics, Appalachain State University.

Longstaff, F. A.- Schwartz, E. S. (1995), “A Simple Approach To Valuing Risky Fixed And Floating Rate Debt.” Journal of Finance, 50, pp. 789-819.

Longstaff, F.A.- Pan, J.- Pedersen, L.H.- Singleton, K.J. (2011), “How Sovereign Is Sovereign Credit Risk”. American Economic Journal: Macroeconomics 3 (2), pp. 75103.

Lumsdaine, R.L.- Papell, D.H. (1997), "Multiple Trend Breaks and the Unit Root Hypothesis”, The Review of Economics and Statistics, 79, pp. 212-218.

Markit, (2008). Markit Credit Indices: A Primer

Merton, R. C. (1974), “On The Pricing of Corporate Debts: The Risk Structure of Interest Rates" Journal of Finance, 29, pp. 449-470.

Ng, S.- Perron, P. (2001), "Lag Length Selection and the Construction of Unit Root Tests with Good Size and Power”, Econometrica, 69, pp. 1519-1554.

Norden, L.- Webber, M. (2009), “The Co-Movement of Credit Default Swap, Bond And Stock Markets: An Empirical Analysis”, European Financial Management, 15, pp. 529-562.

Officer, R. F. (1973), “The variability of the market factor of the New York stock exchange.” Journal of Business, 46, pp. 434-453. 
Oskooee, B. M.- Ng, R. C. W. (2002), Long-run demand for money in Hong Kong: an application of the ARDL model. International journal of business and economics, 1(2), pp. 147-155.

Pan, J.- Singleton, K. (2008), "Default And Recovery Implicit In The Termstructure of Sovereign CDS Spreads.” Journal of Finance 63, pp. 2345-2384.

Paseran, M. H.- Shin, Y.- Smith, R. J. (2001), Bounds Testing Aproachesto The Analysis of Level Relationships, Journal of Applied Econometrics, 16, pp. 289-326.

Perron, P. (1989), “The Great Crash, the Oil Price Shock, and the Unit Root Hypothesis”, Econometrica, 57(2), pp. 1361-1401.

Perron, P. (1997), "Further Evidence on Breaking Trend Functions in Macroeconomic Veriables”, Journal of Econometric, 80, pp. 355-385.

Pu, Xiaoling.- Zhao, Xinlei. (2012), “Correlation in credit risk changes”, Journal of Banking \& Finance, 2012, 36, pp. 1093-1106.

Remolona, Eli.- Scatigna, Michela.- Wu, Eliza. (2008), “The Dynamic Pricing of Sovereign Risk In Emerging Markets: Fundamentals And Risk Aversion”, The Journal of Fixed Income (4), Vol:17, pp. 57-71.

Saikkonen, P. (1992), Estimation and Testing of Cointegrated Systems by an Autoregressive Approximation. Econometric Theory, 8(1), pp. 1-27.

Schwert, G. W. (1989), “Why does stock market volatility change over time?” Journal of Finance, 44, pp. 1115-1153.

Stock, J.- Watson, M.W. (1993), “A Simple Estimator of Cointegrating Vectors in Higher Order Integrated Systems”, Econometrica, 61(4), pp. 783-820.

Tang, D.- Yan, H. (2010), “Market Conditions, Default Risk And Credit Spreads”. Journal of Banking and Finance 34, pp. 743-753.

Toda, H.Y.- Yamamoto, T. (1995), “Statistical Inference In Vector Autoregressions With Possibly Integrated Processes”, Journal of Econometrics, Vol:66, Issue:1-2,pp. 225250.

Zhang, Benjamin. Yibin.- Zhou, Hao.- Zhu, Haibin. (2009), “Explaining Credit Default Swap Spreads with Equity Volatility and Jump Risks of Individual Firms”, Review of Financial Studies, 22, pp. 5099-5131.

Zivot, E.- Andrews, D. (1992), "Further Evidence on the Great Crash, the Oil-Price Shock and the Unit-Root Hypothesis", Journal of Business Economic Statistics, 10(3), pp. 251-270.

https://www.bis.org/publ/otc_hy1711.pdf 